\title{
O COMPORTAMENTO TERAPÊUTICO DA ENFERMEIRA NA HOSPITALIZAÇÃO DA CRIANÇA
}

\author{
Dulce Neves da Rocha :
}

\section{INTRODUÇÃO}

A hospitaização de um adulto determina interrupção de suas atividades e da forma normal de vida, porém, na maioria dos casos, todo o sistema de vida pode ser restabelecido sem grande dificuldade após a alta, quando se consegue a recuperação da saúde. Com a criança o problema assume proporções bem maiores.

Diz Pedro de Alcântara que, "dada a influência das condições de vida e de ambiente sobre a criança e a variada suscetibilidade desta aquelas, conforme suas fases de desenvolvimento, há necessidade de ser EVOLUTIVA a assistência, a fim de adaptar aquelas influências às necessidades de cada uma de tais fases de desenvolvimento" (1).

Para executar satisfatoriamente a sua função é necessário, portanto, que a enfermeira pediátrica esteja segura não apenas das técnicas a serem executadas e dos quadros patológicos específicos, mas também possua conhecimentos suficientes sobre as características de comportamento e as necessidades da criança nas diferentes fases de seu desenvolvimento.

A enfermeira pediátrica, consciente da influência que, como substituta da mãe, pode exercer sobre as crianças a seu encargo, procura desenvolver habilidades especiais para atender a crianças sadias ou doentes nas suas necesidades físicas, emocionais e psíquicas.

\section{REQUISITOS ESSENCIAIS À ENFERMEIRA PEDIÁTRICA}

\section{Gostar de Trabalhar com crianças}

Ao prestar cuidados diretos, a enfermeira tem excelente oportunidade para comunicar-se com a criança. É importante ter sempre em mente que a criança percebe muito facilmente os sentimentos da

* Professôra de Enfermagem Pediátrica da Escola de Enfermagem da U.F.R.J. 
pessoa que a cuida. Mesmo calada a enfermeira pode deixar que a criança perceba instintivamente seu carinho ou sua rejeição. Movimentos bruscos ou descuidados podem produzir na criança dor psíquica tão severa quanto a física.

É claro que não se pretende sugerir um afeto simulado ou exagerado; necessário é que a enfermeira SINTA REALMENTE PRAZER EM TRABALHAR COM CRIANÇAS, com isso ela encontrará sempre a delicadeza e a afetividade a cada ocasião.

\section{Poder de observação}

Se a capacidade de observação é uma qualidade indispensável à enfermeira em qualquer circunstância, quando se trata de crianças isso se torna mais importante. O relatório de enfermagem é sempre a única fonte de informação para orientar o tratamento.

Em pediatria, a enfermeira deve observar e registar não apenas o que diz respeito aos sintomas e sinais que evidenciam a evolução da doença, mas também devem ser observadas as respostas da criança à doença e ao ambiente hospitalar e, mais ainda, as reações dos pais durante todo o tratamento. Só desta forma, a enfermeira conseguirá ajudar a criança a manter-se em equilíbrio e, ao mesmo tempo, contribuir para que o grupo familiar supere a ansiedade.

\section{SITUAÇão dos PAIS ANTE A hOSPITALIZAC̣ão}

Por vezes os pais estão necessitados de ajuda tanto quanto a criança que chega ao hospital. Não faltam razões para um alto grau de tensão emocional dos pais nesse momento, pois a necessidade do afastamento da criança do meio familiar para um hospital leva-os a imaginar a existência de doença grave e raramente há adequada informação sobre o prognóstico. Muito frequentemente os pais sentem-se culpados pelas doenças dos filhos. Em alguns casos a doença pode estar ligada a falta de cuidado ou a desajustamentos no lar, em outros prevalecem os fatores hereditários ou os fatores sócio-econômicos da família e, quase sempre a prevenção da coença foge a qualquer cogitação, mesmo quando se trata de pais cuidadosos, devendo-se levar em conta outras razões influenciadas por fatores culturais, tipo de educação, ou mesmo por experiências com hospitalizações anteriores fazendo com que os pais temam a perda da afeição dos filhos durante a hospitalização prolongada, resumindo-se em fonte de ansiedade que interfere intensamente nas reações que apresentam.

Cabe à enfermeira compreender e tentar amenizar as expressões de ansiedade dos pais. A melhor maneira de tranqüilizar a famí- 
lia é explicar de modo simples e dentro dos limites da ética profissional, a situação da criança, é mostrar-se realmente interessada em ajudar. A mãe sentir-se-á confortada ao compreender que seu filho está entregue a pessoas interessadas e responsáveis e que se esforçarão no sentido de ajudar a criança a recuperar a saúde e retornar ao lar no menor tempo possível.

\section{admissão ao hospital pediátrico}

Numa sala de espera de hospital ou mesmo no ambulatório encontram-se crianças e pais sofrendo diversos graus de ansiedade. Poucos estão preparados para a situação que enfrentam. A maioria conserva-se na mais completa ignorância sobre o que está para acontecer.

É indispensável que a enfermeira nunca se esqueça de que tanto o comportamento dos pais como dos filhos em relação a doença e ao hospital, a partir desse momento, depende em grande parte desse primeiro contato.

Todo o pessoal do setor de registro e ambulatório de um hospital deve ser adequadamente treinado para atender corretamente a clientela. Informações precisas e cortesia no relacionamento são elementos inispensáveis para inspirar confiança.

Quando está indicada a internação é necessário preparar a criança adequadamnete desde que ela seja capaz de compreender. Ao receber uma criança para internar a enfermeira deverá averiguar o que ela sabe a respeito do hospital, inclusive se sabe que veio para ficar, pois talvez ela ainda ignore o fato.

A enfermeira necessita obter dados referentes a vida cla criança, seus hábitos, suas capacidades físicas e intelectuais, seus interesses. Para registrar essas informações é interessante utilizar uma folha ou ficha que auxiliará no planejamento de cuidados de enfermagem, essencialmente porque indicará o grau de regressão que a doença poderá estar determinando na criança. Uma vez que as questões formuladas para obter informações sobre uma criança na primeira infância diferem muito daquelas formuladas para obter dados de um pré-escolar ou escolar, sugerimos dois modelos de questionários que são utilizados como material de ensino de Enfermagem Pediátrica (anexos I e II).

\section{PREOCUPAÇÕES DA ENFERMEIRA AO RECEBER UMA CRIANÇA EM HOSPITAL}

1. Identificar o grau de ansiedade dos pais e da criança.

2. Procurar saber até onde os pais e a criança estão bem informados sobre a doença seu prognóstico e a vida hospitalar. 
3. Explicar aos pais a finalidade de certos procedimentos, e dar, dentro dos limites éticos, todos os esclarecimentos por eles solicitados.

4. Evitar que a criança ouça o que não pode entender. Será ininteressante que a enfermeira converse com a mãe enquanto o médico examina a criança.

4. Evitar que a criança ouça o que não pode entender.

5. Permitir que a mãe participe do cuidado prestado à criança no ato da admissão.

6. Anotar rigorosamente qualquer fato importante do comportamento da criança, suas relações com a mãe e outros familiares.

7. Permitir que a mãe veja a unidade da criança e permaneça com a mesma até que se acalme.

8. Julgar com inteligência a rotina de admissão a fim de modificá-la sempre que isso for necessário, de modo a obter melhor colaboração da criança.

9. Evitar que a mãe se retire às escondidas.

10. Procurar familiarizar a criança com o novo ambiente.

11. Fazer-se amiga da criança.

12. Fazer com que a criança sinta que terá no hospital "um lugar seu".

13. Ao planejar os cuidados de enfermagem, ter em mente que os problemas decorrentes da doença e da hospitalização poderão estar interferindo em vários graus no processo de desenvolvimento da criança.

\section{FATORES QUE INTERFEREM NA ADAPTAÇÃO \\ DA CRIANÇA AO hOSPITAL}

1. Idade da Criança - A enfermeira, conhecendo bem as características de cada fase da evolução da infância, procurará atender as necessidades da criança, de acordo com sua idade, respeitando as diferenças individuais que presidem as reações de cada ser humano.

2. Problemas decorrentes de experiência anteriores - São talvez, os que mais decisivamente influem na adaptação da criança ao hospital. Decorrem do atendimento inadequado às suas necessidades básicas, desde os primeiros momentos de sua vida. A criança acostumada a ser bem tratada, a não ser enganada, sente-se em geral segura e enfrenta bem as situações, confiando sempre nas pessoas que a cercam. O mesmo não acontece com aquelas cujas experiências com a mãe redundaram em frustrações. Estudos realizados por psicólogos provam que crianças 
procedentes de asilos e orfanatos reagem sempre mal a hospitalização.

3. Significado da Doença para a Criança - A boa interação com a criança pode permitir à enfermeira o conhecimento do que a criança "pensa" sobre sua própria doença. E haverá então oportunidade para esclarecê-la sempre que isso se fizer necessário, mesmo que, nos casos mais complexos, haja necessidade de encaminhamento a psicólogos.

4. Grau de sofrimento imposto pela doença - O sofrimento físico aliado a separação da família pode influir negativamente sobre a adaptação da criança ao hospital. Por outro lado, há uma tendência geral de nos aproximarmos dos doentes cujo sofrimento físico seja reconhecido, mas nem sempre conseguimos avaliar e atender devidamente aqueles que sofrem em silêncio, por temores e ansiedade. É frequente encontrarmos crianças caladas, "boazinhas", que passam pelo hospital sem chamar a atenção de ninguém e, talvez saiam de lá com marcas in_ deléveis em sua personalidade.

5. Contatos com a mãe durante a hospitalização - Já no ato de admissão a mãe pode ajudar a despir, pesar, medir, etc., isso tanto ajuda a mãe que pode estar ansiosa com a perspectiva de perder o carinho do filho durante a separação, quanto faz a criança sentir-se mais segura por ter a presença da mãe enquanto é cuidada por estranhos. Esse trabalho conjunto permite à enfermeira observar as relações entre mãe - filho, e melhor favorece a adaptação da criança ao hospital. As rotinas do hospital devem ser bastante flexíveis para permitirem as mudanças indicadas para atender às necessidades de cada criança.

6. A atenção recebida no Hospital - $A$ adaptação da criança poderá ser facilitada através do pessoal do hospital que deverá procurar aliviar a ansiedade em todas as situações difíceis, e pelo atendimento às necessidades específicas da fase da vida que a criança está atravessando. Podemos enumerar, entre outros, os seguintes itens de importância para diminuir a ansiedade e o sofrimento da criança durante a hospitalização:

a) Preparo para experiências dolorosas;

b) Evitar que presencie tratamentos traumatisantes e impressionantes;

c) Evitar comentários sobre sua doença ou de outras crianças;

d) Esclarecer as dúvidas da criança em relação ao seu futuro;

e) Esclarecer a criança quando perceber que ela relaciona seu estado com o de outra mais grave ou que faleceu;

f) Evitar que a criança receba o tratamento como castigo; 
g) Facilitar ao máximo as visitas dos pais, quando não for possível a sua permanência definitiva no hospital.

O atendimento a todas as necessidades da criança só se realiza_ adequadamente quando é elaborado um plano de cuidado levandose em conta as características individuais da criança, sua fase de desenvolvimento e crescimento e seu quadro patológico. Esse planejamento e sua implementação é tarefa específica da enfermeira. Pode ser feito em folhas próprias, livro, ficha Kardex, etc.; o importante é que seja escrito e assinado pela enfermeira, a qual será responsável pelo seu conteúdo. Constitui esse plano um guia que norteará todo o pessoal auxiliar na prestação de cuidados à criança.

T'emos utilizado nos estágios um modelo simples (anexo III) que exige pouco tempo para seu preenchimento, desde que a enfermeira esteja a par das necessidades de seu paciente. Consta de uma parte para identificação da criança, outra onde, são registradas as necessidades básicas com espaços onde serão indicados as formas de satisfazê-las e finalmente um espaço onde serão descritas as condições específicas da criança e os respectivos cuidados de enfermagem.

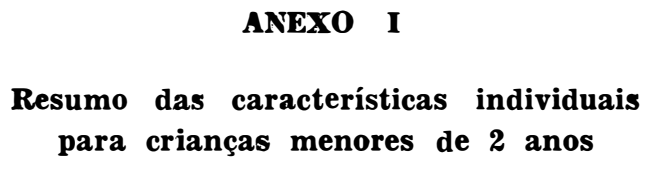

Nome Idade Sexo

Como é chamado em casa

\section{CARACTERISTICAS DO DESENVOLVIMENTO MOTOR}

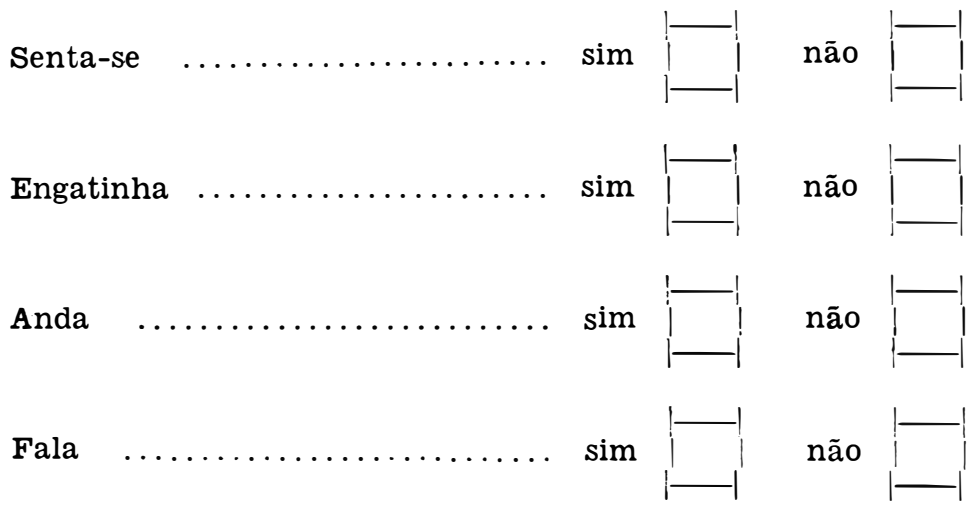




\section{HÁBITOS ALIMENTARES}

suga em mamadeira $\operatorname{sim}$

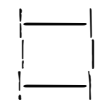

não<smiles>[IH]1[IH][IH][IH]1</smiles>

toma o alimento em copo ...... sim

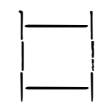
não

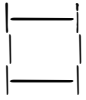

não

Toma sopa em prato

$\operatorname{sim}$

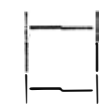

Alimenta-se à noite

$\operatorname{sim}$

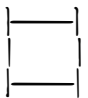

não

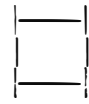

Alimenta-se à noite

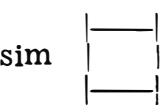

não

\section{HÁBITOS DE SONO}

Dorme só

$$
\operatorname{sim}
$$

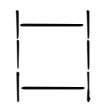

não

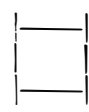

Dorme em berço

$\operatorname{sim}$

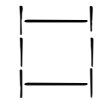

não

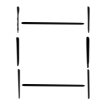

Dorme com os pais

$\operatorname{sim}$

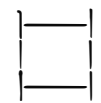

não

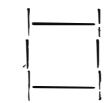

Dorme em cama c/outras pessoas sim

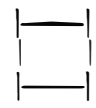

não

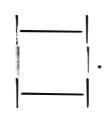

Acorda durante à noite

$\operatorname{sim}$

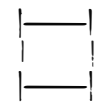

não

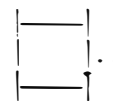

4. VIVE COM OS PAIS

$\operatorname{sim}$

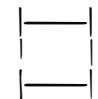

não

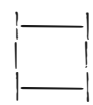

5. CUIDADO PELA MÃ $\operatorname{sim}$

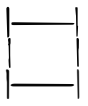

não

6. Descreva em poucas palavras como lhes pareceu a relação Materno-Infantil. 
7. Outras Observações

\section{ANEXO II \\ PARA CRIANÇAS MAIORES DE 2 ANOS RESUMO DAS CARACTERISTICAS INDIVIDUAIS}

NOME:

IDADE .... SEXO ...... COMO É CHAMADA EM CASA

N. ${ }^{\circ}$ DE IRMÃOS IDADES

N. DE IRMÃS IDADES

\section{HÁBITOS ALIMENTARES}

Leite que vem usando?

Suga em mamadeira? $\operatorname{sim}$

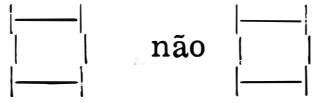

Toma o alimento em copo? $\operatorname{sim}$<smiles>C1[IH][IH][IH]1</smiles>
não<smiles>C1[IH][IH][IH]1</smiles>

Alimenta-se à noite? $\operatorname{sim}$<smiles>[I-]1[IH][IH]1</smiles>
não

Tem bom apetite? $\operatorname{sim}$<smiles>[IH]1[IH][IH][IH]1</smiles>
não<smiles>[I-]1[IH][IH]1</smiles>

Alimenta-se em prato?

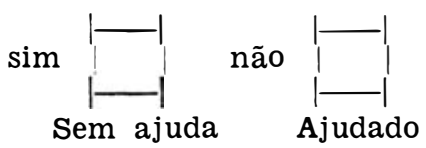

Alimentos preferidos

\section{HábITOS DE SONO}

Onde dorme - Berço 
c/os pais ${ }_{-}$c/outra pessoa $|+|$

Faz asseio corporal antes de deitar-se? sim
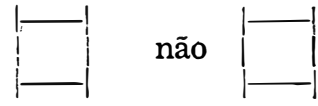

Acorda durante

a noite

$\operatorname{sim}$

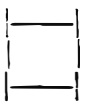

não

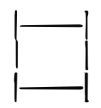

Tem medo de escuro?

$\operatorname{sim}$

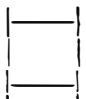

não

1

Faz oração antes de dormir? .... sim

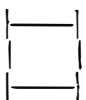

não

\section{HÁBITOS DE ELIMINAÇÃO}

- Como expressa a necessidade de urinar?

- Como expressa a necessidade de evacuar?

- No vaso sanitário<smiles>C1[IH][IH][IH]1</smiles>

- No urinol

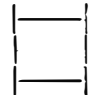

- No troninho

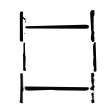

- No chão

- Urina na cama? $\operatorname{sim}$
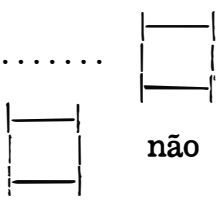
não

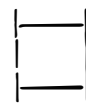

- É acordado para urinar $\operatorname{sim}$<smiles>C1[IH][IH][IH]1</smiles>
não<smiles>C1[IH][IH][IH]1</smiles>

\section{HÁBITOS DE HIGIENE CORPORAL}

De que forma toma banho: bacia<smiles>C1[IH][IH][IH]1</smiles>
Outro

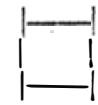

Chuveiro

Banheira ou 
Toma banho sozinho

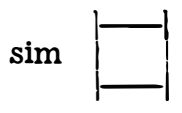
não $\operatorname{sim}$

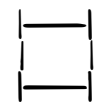
não

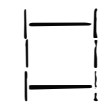

Lava as mãos
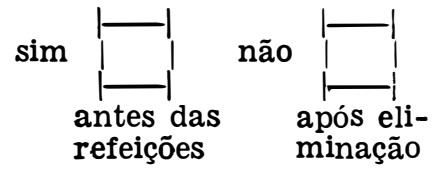

\section{BRINQUEDOS PREFERIDOS}

1.

2. Peça à, mãe ou responsável que traga o brinquedo preferido sempre que possível.

6. ESCOLARIDADE

\section{TEM “TICS"?}

Quais?

8. A criança vive com seus pais? (em caso negativo cite com quem vive)

9. Descreva em poucas palavras com que lhe pareceu a relação Materno-Infantil?

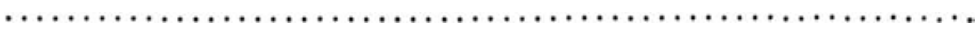

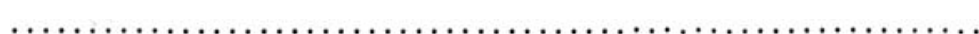

10. A criança sabe que ficará no hospital? ...... sim

a) Como reagiu ao seu informado?

não

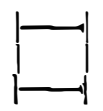

b) Em caso negativo, diga agora junto a mãe

- e agora como reagiu? 


\section{OUTRAS OBSERVAÇÕES}

ANEXO III

ESCOLA DE ENFERMAGEM DA U.F.R.J.

DEPARTAMENTO DE ENFERMAGEM MATERNO-INFANTIL

DISCIPLINA: ENFERMAGEM PEDIÁTRICA

PLANO DE CUIDAdOS DE ENFERMAGEM

NOME:

DATA DO NASCIMENTO .../.......

SEXO:

CÔR:

ADMISSÃO:

PARECER DA ENFERMAGEM:

ATUALIZADO POR:

EM

\begin{tabular}{|c|c|}
\hline NECESSIDADES & CUIDADOS GERAIS \\
\hline Alimentação & $\begin{array}{c}\text { Mamadeira ........... Prato } \ldots \text { P........... Sonda } \\
\text { Ver cond. Específica }\end{array}$ \\
\hline Hidra & $\begin{array}{c}\text { Livre ........... Entre Refeições } \\
\text { Ver cond............ Parenteral ............ Específica }\end{array}$ \\
\hline Eliminações & 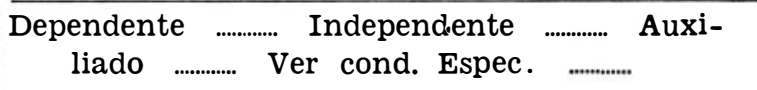 \\
\hline Higiene & $\begin{array}{c}\text { Chuveiro ............ Banheira } \\
\text { Ver Cond. Específica }\end{array}$ \\
\hline Atividade & Livre ............ Limitada ............. Ver. Cond. Espec. ........... \\
\hline Recreação & 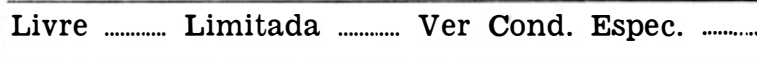 \\
\hline T.P.R. & Manhã e Tarde $\quad . . . . . . . . . . . \quad$ Ver Cond. Espec. \\
\hline T. Arterial & 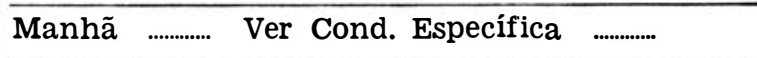 \\
\hline Peso & 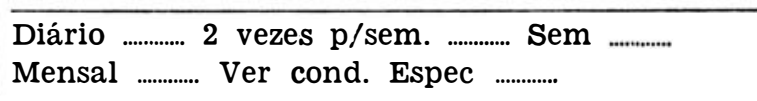 \\
\hline
\end{tabular}




\section{REFERENCIAS BIBLIOGRÁFICAS}

AlCANTARA, Pedro e Marcondes, E. - Pediatria Básica.

CARDOSO, Ofélia Boisson, Problemas da Infância. 1964. Edições Melhoramentos, São Paulo.

BOWLBY, J. Cuidados Maternos Y Salud Mental. Publicaciones Cientificas, n..$^{\circ}$ 14, OMS - 1954.

FONTES, Flávio D'Andres, Aspectos psicológicos da Hospitalização Infantil. Revista Brasileira de Enfermagem XV - 5-1962.

JEANS, Blake e Wright. Enfermeria Pediátrica. Editorial Interamericana. México, 1965.

PERALES, Maria. Atitude em Enfermagem Pediátrica. Revista de Enfermagem - Outubro de 1963.

PLANK, Emma - El cuidado emocional del niño en el Hospital, Buenos Aires, 1966. 